\section{Water works}

\section{John Lloyd}

Journal of Contaminant Hydrology. Editors R.W. Gillham. G. Matthess, P.L. McCarty and P.S.C. Rao. Elsevier. 4/yr. Dfl. 286 .

Journal of Contaminant Hydrology is a very welcome addition to the literature. It fills an essential gap by providing the opportunity to bring together scientific material in an increasingly important field; to date papers on this subject have been dispersed in a variety of lessscientific publications.

The title, however, is unfortunately somewhat misleading as the journal's scope emphasizes groundwater contamination. including the unsaturated and saturated zones but not surface water contamination unless related to groundwater. Investigations of the physical, chemical and biological processes that influence organic and inorganic contaminants will be considered for publication.

The contents of Vol 1 (1986-1987) are dominated by papers on organic contaminants, with Parts 1 and 2 devoted to a special introductory issue on the topic The volume includes a good mix of theoretical papers and applied case-studies, which one hopes will continue in future. The standard of the papers is high and readily comparable with the Journal of Hydrology, also published by Elsevier.

There appears to be no limitation on length of contributions, with most papers being some $10-20$ pages inclusive of illustrations. The quality of production and illustration is of the usual high Elsevier standard, and the subscription price is reasonable. For the first volume the time elapsed between paper submission and acceptance was typically six to nine months. In addition to the scientific papers conference announcements are included.

Contaminants in groundwater pose some very real difficulties for scientists, engineers and administrators, and I hope that the editors will acknowledge the practicalities of the subject in future issues. I also hope that they will make the journal a truly international forum and get away from the North American bias of the first volume.

John Lloyd is a Professor in the Department of Geological Sciences, University of Birming. ham, PO Box 363, Birmingham, BI5 2TT, UK.

\section{Fruits of the tree of knowledge}

\section{John C. Marshall}

Cognitive Development. Editor Wendell E. Jeffrey. Ablex, 355 Chestnut Street, Norwood, New Jersey 07648. 4/yr. \$58.50 (institutional), $\$ 27.50$ (individual).

Language and Cognitive Processes. Coordinating editor Lorraine K. Tyler. VNU. 4/yr. DM 197, $\$ 94$ (institutional); DM 134, \$64 (individual).

'Cognition' has been the buzz word in psychology for the past 20 years, a notable span in a discipline where fashions wax and wane with the regularity of pop groups. Even now, no new title can avoid the incantation that spells a superior attitude to the study of mind. I sometimes think that before retiring to bed, modish authors and editors recite to themselves: "Lord, I thank thee I am not like other men, behaviourists, illogical positivists, or even like this stamp collector".

The original motive was that cognitive psychology should extricate itself from the follies of classical and operant conditioning and admit that a lot of very complex information-processing goes on inside the (even) average head. The guiding idea was that computationally explicit accounts of the mechanisms that underlie higher mental functions could be formulated and evaluate the details of the evidence

Many of the papers, however, are disappointing - solid, competent pieces of research but with little spark or excitement. The authors have not asked themselves why they undertook this particular experiment, and they report their work in singularly depressing and turgid English. Developmental psychologists appear

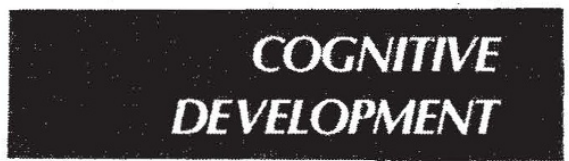

prone to imagine that a difference between performance at two ages is intrinsically fascinating. They are wrong. Yet some bright spots stand out, most notably a paper by Gelman and her colleagues on young children's numerical competence. One can actually hear the authors thinking about the interaction of principles and procedures that determines the acquisition of counting skills. For the rest, the journal has not yet achieved a style of its own, and the contributions would not be out of place in myriad other journals of child development.

Language and Cognitive Processes is edited from the Department of Experimental Psychology in Cambridge. It has a distinguished editorial board drawn from three continents, and it takes its 'cognitive' label seriously. Although the journal is devoted principally to the psychology of language perception and production, contributors are not afraid to draw upon linguistic theory for accounts of the structures that performance machinery encodes and decodes; neither do they hesitate to invoke the guts of sentence parsing by computer and the psychological validity thereof.

Most of the papers deal with core topics in lexical and syntactic processing by normal adults, and they include excellent work on languages other than English. Two fine studies focus on developmental issues: Miller on the conjunction of vocabulary learning and automated dictionaries, and Karmiloff-Smith on the changing linguistic forms that children deploy in cohesive narratives. The value of neuropsychological evidence for elucidating the functional architecture of cognitive skill is well illustrated by the investigation of Goodman and Caramazza into spelling impairment after closedhead injury; likewise, a case study of paraphasic errors enables Pate, Saffran and Martin to refine a model of normal language production.

Although some papers are tough going, the effort to follow them will be amply repaid. This journal has already secured a genuinely cognitive niche, hitherto vacant.

John C. Marshall is in the Neuropsychology Unit, part of the Neuroscience Group at the Radcliffe Infirmary, Oxford $O X 26 \mathrm{HE}$, UK. 